\title{
Long-term quality of life and sexual function of elderly people with endometrial or ovarian
} cancer

\begin{abstract}
Ariane Mamguem Kamga ${ }^{1 \dagger}$, Leila Bengrine-Lefevre ${ }^{2,3 \dagger}$, Valérie Quipourt ${ }^{3,4}$, Laure Favier ${ }^{2}$, Ariane Darut-Jouve ${ }^{5}$, Sophie Marilier ${ }^{3,4}$, Patrick Arveux ${ }^{1,6}$, Isabelle Desmoulins ${ }^{2}$ and Tienhan Sandrine Dabakuyo-Yonli ${ }^{17^{*}}$ (D)
\end{abstract}

\begin{abstract}
Background: With the growing number of older endometrial cancer (EC) and ovarian cancer (OC) survivors, data on long-term health-related quality of life (HRQOL) became an important issue in the management of older patients. So, the aim of this study was to describe and compare according to age long-term HRQoL, sexual function, and social deprivation of adults with either EC or OC.

Methods: A cross-sectional study was set up using data from the Côte d'Or gynecological cancer registry. A series of questionnaires assessing HRQoL (SF-12), sexual function (FSFI), anxiety/depression (HADS), social support (SSQ6) and deprivation (EPICES) were offered to women with EC or OC diagnosed between 2006 and 2013. HRQoL, sexual function, anxiety/depression, social support and deprivation scores were generated and compared according to age ( $<70$ years and $\geq 70$ years).
\end{abstract}

Results: A total of 145 women with EC $(\mathrm{N}=103)$ and OC $(\mathrm{N}=42)$ participated in this study. Fifty-six percent and $38 \%$ of $E C$ and $O C$ survivors respectively were aged 70 and over. Treatment did not differ according to age either in OC or EC. The deprivation level did not differ between older and younger survivors with OC while older survivors with EC were more precarious. The physical HRQoL was more altered in older EC survivors. This deterioration concerned only physical functioning ( $M D=24, p=0.012)$ for $O C$ survivors while it concerned physical functioning $(M D=30$, $p<0.0001)$, role physical ( $M D=22, p=0.001)$ and bodily pain $(M D=21, p=0.001)$ for $E C$ survivors. Global health $(\mathrm{MD}=11, p=0.011)$ and role emotional $(\mathrm{MD}=12, p=0.018)$ were also deteriorated in elderly EC survivors. Sexual function was deteriorated regardless of age and cancer location with a more pronounced deterioration in elderly EC survivors for desire $(p=0.005)$, arousal $(p=0.015)$ and orgasm $(p=0.007)$. Social support, anxiety and depression were not affected by age regardless of location.

Conclusion: An average 6 years after diagnosis, the impact of cancer on HRQoL is greatest in elderly survivors with either EC or OC.

Keywords: Health-related quality of life, Endometrial cancer, Ovarian cancer, Old patients

*Correspondence: sdabakuyo@cgfl.fr

${ }^{\dagger}$ Ariane Mamguem Kamga and Leila Bengrine-Lefevre contributed equally to this work

${ }^{1}$ Epidemiology and Quality of Life Research Unit, Lipids, Nutrition, Cancer Research Center, INSERM U1231, Georges Francois Leclerc Centre - UNICANCER, 1 rue Professeur Marion, BP 77980, 21079 Dijon Cedex, France

Full list of author information is available at the end of the article

\section{Background}

Endometrial and Ovarian cancers are primarily a disease of older people with median age at diagnosis respectively of 69 and 68 years old [1]. With population living longer, the number and proportion of older adults will increase, along with the incidence of both endometrial and ovarian original author(s) and the source, provide a link to the Creative Commons licence, and indicate if changes were made. The images or other third party material in this article are included in the article's Creative Commons licence, unless indicated otherwise in a credit line to the material. If material is not included in the article's Creative Commons licence and your intended use is not permitted by statutory regulation or exceeds the permitted use, you will need to obtain permission directly from the copyright holder. To view a copy of this licence, visit http://creativecommons.org/licenses/by/4.0/. The Creative Commons Public Domain Dedication waiver (http://creativeco mmons.org/publicdomain/zero/1.0/) applies to the data made available in this article, unless otherwise stated in a credit line to the data. 
cancer [2, 3]. Elderly women with endometrial cancer have histologically aggressive tumors and are frequently diagnosed at advanced stages of the disease $[4,5]$. Ovarian cancer (OC) in elderly women is mainly diagnosed at a higher stage [6, 7]. Managing cancer in older people is very complex. Older people with cancer generally are likely to have several comorbidities with polypharmacy as consequences and physiologic age-related changes [8]. Surgical treatment completed by adjuvant radiotherapy and systemic therapy depending on the stage of disease is the standard treatment for endometrial cancer [9]. For OC, treatment include surgical staging and cytoreduction as well as systemic chemotherapy, either as adjuvant treatment or neoadjuvant therapy before surgery [10]. Despite recommendations, older women with endometrial or ovarian cancer are undertreated $[4,11]$ and underrepresented in clinical trials [12]. Outcomes in older women with $\mathrm{OC}$ is known to be worse. Indeed, older patients with OC show an impaired survival prognosis compared to younger patients [2, 11]. For elderly patients with endometrial cancer (EC), cancer specific survival rate was lower among the elderly and very elderly women than among their younger counterparts $[5,13,14]$. With the growing number of older endometrial and ovarian cancer survivors, data on long-term health-related quality of life (HRQoL) became an important issue in the management of older patients. Few studies has focused on this issue in regard with long term. So, the aim of this study was to describe and compare according to age the long-term HRQoL, sexual function, and social deprivation of people with endometrial or ovarian cancer.

\section{Methods}

This study is an ancillary study. The primary study aimed to identify determinants of long term HRQoL in women with cervical, endometrial and ovarian cancer and to describe their living conditions. The main study was performed in accordance with the Declaration of Helsinki and have received ethics approval. Indeed, the study was approved by the french national data protection authority (Commission nationale de l'informatique et des libertés MR003 $\mathrm{N}^{\circ} 1989764$ V.0). Also, women have received legal information about the study. The response to the questionnaires constituted the women's consent to participate. Details regarding the study design, sample, and methods have been previously reported [15]. For this study, eligible participants were required to be women aged 18 years old and more; to be diagnosed with endometrial or ovarian cancer between 2006 and 2013; to be identified through Côte d'Or breast and gynecological cancer registry and to be alive on the 1st January 2017. The Côte d'Or breast and gynecological cancer registry is the only one in France to focus on breast and gynecologic cancers. It has been collecting data on all cases of breast and gynecologic cancer occurring in residents of Côte d'Or since 1982.

Concerning data collection, clinical characteristics like age at diagnosis, stage, treatments, comorbidities, hormonal status were extracted from the breast and gynecological cancers registry of Côte d'Or.

Age at the time of survey was also collected. In January 2017, women eligible received a mail including an information letter and some questionnaires. These questionnaires included the Medical Short-Form 12 (SF-12) [16] to assess HRQoL, the Female Sexual Function Index (FSFI) $[17,18]$ for sexual function, the hospital anxiety and depression scale (HADS) [19] for anxiety/depression, the Sarason social support questionnaire (SSQ6) [20] for social support and the EPICES (Évaluation de la précarité et des inégalités de santé pour les centres d'examen de santé) questionnaire [21] for individual deprivation. In the absence of any response from patients within 1 month, a reminder was sent.

The Medical Outcomes Study 12-item Short Form health survey (SF-12) is a validated tool used to assess general HRQoL [16]. It comprises eight scales and two summary scales, namely the Physical Component Summary (PCS) and the Mental Component Summary (MCS) can be computed from the eight scales.

The Female Sexual Function Index (FSFI) is a selfreported measurement of sexual functioning developed by Rosen [17]. A French version has been validated in women including those with cancer [18]. This 19-item questionnaire explores sexual function in six dimensions: desire, arousal, lubrication, orgasm, sexual satisfaction, and pain of intercourse.

The Hospital Anxiety and Depression Scale (HADS) is an instrument for detecting anxiety and depressive disorders. It was validated and adapted in French in 1989 by Lepine et al. [19]. This scale has 14 items rated from 0 to 3 and covers 2 dimensions.

Sarason's six-item Social Support questionnaire (SSQ6) is a validated tool adapted in French by Rascle et al. [20]. This questionnaire reflects the support available in patients' environment. Social support is measured across 2 dimensions: support availability, through the number of contacts that the patient can count on (0 to 9 people) and quality of support, through patient satisfaction with support received.

The EPICES questionnaire [21] is a questionnaire developed specifically for the French context that contains 11 items that take into account the overall living conditions. It explores individual deprivation and social health and discriminates the most deprived (score $>30$ ) from non-deprived individuals (score $\leq 30$ ). 
For each location, we compared respondents and non-respondents on their clinical and personal characteristics. Clinical and personal characteristics were also compared according to age for the two locations. We performed univariate analyses to compare HRQOL, sexual function, anxiety/depression, social support and individual deprivation scores for each location and according to age at the time of the survey ( $<70$ years and $\geq 70$ years). A $p$ value lower than 0.05 was set to define a statistically significant difference. We also performed a mixed regression model on clinically meaningful HRQoL dimensions to found if age was a significant determinant of HRQoL adjusted on other variables. We define clinically meaningful HRQoL dimensions as dimensions in which the mean difference between older and younger were more than 10 points. The eligibility threshold for the multivariable model was a $p$ value less than 0.20 .

\section{Results}

\section{Characteristics}

Three hundred and fourteen women was eligible and 145 (46\%) women participated to the study. Among them, we have respectively 103 and 42 women with EC and OC. There is a significant difference between responders and non-responders for EC in terms of time since diagnosis (Table 1). Women with a longer time since diagnosis were reluctant to participate to the study $(p=0.01)$.

Fifty-six percent and $38 \%$ of endometrial and ovarian cancer survivors were aged 70 and over respectively by the time of the survey. Treatments did not differ between younger and older survivors in both cancer locations ( $p=0.48$ for EC and $p=0.72$ for OC). While OC survivors were treated mostly with chemotherapy, EC survivors on their own were treated with radiotherapy. The level of individual deprivation did not differ between older and younger OC survivors, while older survivors with EC were more precarious. The complete description of endometrial and ovarian cancer survivors are displayed in Table 2.

\section{HRQoL, sexual function, social support, anxiety and depression}

Among ovarian cancers survivors, HRQoL was not good. The mean physical component score was $49( \pm 7.5)$ for younger ones and $40.8( \pm 10.5)$ for older ones. Physical functioning $(\mathrm{MD}=24, p=0.01)$ was the only dimension statistically and clinically meaningful among OC survivors; bodily pain $(\mathrm{MD}=14, p=0.1)$ and role physical $(\mathrm{MD}=15, p=0.08)$ were only clinically meaningful. Sexual function was impaired regardless of age. See Table 3 for more details.

Among older survivors with EC, the physical component of HRQoL was more degraded compared to younger ones. Indeed, EC survivors aged less than 70 years old have a mean physical component score of $48.2( \pm 10.6)$ while the older ones have a score of $37.8( \pm 9.9)$. Physical functioning $(\mathrm{MD}=30, p<0.001)$, role physical $(\mathrm{MD}=22$, $p=0.001)$ and bodily pain ( $\mathrm{MD}=21, p=0.001)$, general health $(\mathrm{MD}=11, p=0.01)$ and role emotional $(\mathrm{MD}=12$, $p=0.02$ ) were the dimensions statistically and clinically meaningful among EC survivors. Sexual function was impaired regardless of age with greater deterioration in EC survivors aged 70 and over for the dimensions desire $(p=0.01)$, arousal $(p=0.01)$ and orgasm $(p=0.01)$. The complete description of HRQoL and sexual function could be found in Table 4 .

Social support, anxiety and depression were not affected by age regardless of location (Table 5 ).

Age was a significant determinant for physical functioning and bodily pain subscales among EC survivors whereas it was significant only for physical functioning among OC survivors when adjusting on others variables (Table 6).

\section{Discussion}

This study analyzed 103 women with EC and 42 women with $\mathrm{OC}$ with an average time since diagnosis of 6 years. As shown in the original study, HRQoL was deteriorated among women with EC and OC. The results of this study indicate that this deterioration was more pronounced in older women with EC. Indeed, older women with EC in this study had a worst score on all subscales except mental health, social functioning and vitality compared to youngers ones.

Age was found as great determinant of physical functioning and bodily pain for EC survivors. For women with OC, age was a significant determinant of HRQoL. Physical functioning was impaired among older survivors compared to younger ones.

With advancing age, many changes occur which affect all the organs system. These changes led to age-related diseases, functional changes capacities and ultimately to organ failures [22]. Older patients with gynecological cancer are not exception. Indeed, they may have aging-associated frailties associated with comorbidities and geriatric syndromes. There was a more pronounced physical impairment among older survivors with EC as opposed to older OC survivors. This could be explained by the impact of treatment but also comorbidities which are more present in patient with EC. Medical problems such as hypertension, obesity, articular dysfunction can lead to a worse functional status and vitality impairment. EC survivors in this study were treated primarily with radiotherapy. Unlike chemotherapy known for its short-term effects, radiotherapy can have a significant physical impact in the long term 
Table 1 Comparison between responders and non-responders in ovarian and endometrial cancer survivors

\begin{tabular}{|c|c|c|c|c|c|c|c|c|c|c|}
\hline \multirow[t]{3}{*}{ Variables } & \multicolumn{5}{|c|}{ Ovarian Cancer Survivors } & \multicolumn{5}{|c|}{ Endometrial cancer survivors } \\
\hline & \multicolumn{2}{|l|}{ Responders } & \multicolumn{2}{|l|}{ Non-responders } & \multirow[t]{2}{*}{$p$} & \multicolumn{2}{|l|}{ Responders } & \multicolumn{2}{|l|}{ Non-responders } & \multirow[t]{2}{*}{$p$} \\
\hline & $\mathrm{N}=42$ & $\%$ & $\mathrm{~N}=27$ & $\%$ & & $N=103$ & $\%$ & $N=142$ & $\%$ & \\
\hline Time since diagnosis ( $m$ ) & & & & & 0.79 & & & & & 0.06 \\
\hline Mean (SD) & $76.1(27.1)$ & & $77.8(26.5)$ & & & $80.2(29.3)$ & & $87.2(26.3)$ & & \\
\hline Median [range] & $71.0[39.0-127.0]$ & & $73.0[37.0-127.0]$ & & & $76.0[36.0-131.0]$ & & $90.5[37.0-130.0]$ & & \\
\hline Age at diagnosis (years) & & & & & 0.92 & & & & & 0.85 \\
\hline Mean (SD) & $59.1(12.5)$ & & $60.1(13.7)$ & & & $65.1(9.4)$ & & $65.0(9.0)$ & & \\
\hline Median [range] & $59.5[20.0-82.0]$ & & $59.0[30.0-88.0]$ & & & $65.0[42.0-86.0]$ & & $65.0[37.0-86.0]$ & & \\
\hline Time since diagnosis & & & & & 0.6 & & & & & 0.01 \\
\hline$<5$ years & 15 & 35.7 & 8 & 29.6 & & 34 & 33.0 & 27 & 19.0 & \\
\hline$\geq 5$ years & 27 & 64.3 & 19 & 70.4 & & 69 & 67.0 & 115 & 81.0 & \\
\hline Stage & & & & & 0.75 & & & & & 0.25 \\
\hline । & 17 & 41.5 & 13 & 48.1 & & 94 & 92.2 & 121 & 85.2 & \\
\hline$\|$ & 5 & 12.2 & 4 & 14.8 & & 3 & 2.9 & 9 & 6.3 & \\
\hline III & 19 & 46.3 & 10 & 37.1 & & 5 & 4.9 & 12 & 8.4 & \\
\hline Unknown & 1 & & 0 & & & 1 & & 0 & & \\
\hline Hormonal status & & & & & 0.56 & & & & & $>0.99$ \\
\hline Postmenopausal & 35 & 83.3 & 21 & 77.8 & & 100 & 97.1 & 137 & 96.5 & \\
\hline Not postmenopausal & 7 & 16.7 & 6 & 22.2 & & 3 & 2.9 & 5 & 3.5 & \\
\hline $\mathrm{CCl}$ & & & & & 0.43 & & & & & $>0.99$ \\
\hline 0 & 23 & 88.5 & 15 & 79.0 & & 60 & 66.7 & 84 & 66.7 & \\
\hline$\geq 1$ & 3 & 11.5 & 4 & 21.0 & & 30 & 33.3 & 42 & 33.3 & \\
\hline Unknown & 16 & & 8 & & & 13 & & 16 & & \\
\hline Surgery & & & & & 0.39 & & & & & 0.41 \\
\hline Yes & 42 & 100.0 & 26 & 96.3 & & 100 & 99.1 & 142 & 100.0 & \\
\hline No & 0 & 0.0 & 1 & 3.7 & & 1 & 0.9 & 0 & 0.0 & \\
\hline Unknown & & & & & & 2 & & & & \\
\hline Chemotherapy & & & & & 0.51 & & & & & 0.50 \\
\hline Yes & 31 & 73.8 & 21 & 80.8 & & 5 & 4.9 & 10 & 7.0 & \\
\hline No & 11 & 26.2 & 5 & 19.2 & & 96 & 95.1 & 132 & 93.0 & \\
\hline Unknown & 0 & & 1 & & & 2 & & 0 & & \\
\hline Radiotherapy & & & & & 0.39 & & & & & 0.06 \\
\hline Yes & 0 & 0.0 & 1 & 3.7 & & 67 & 66.3 & 108 & 77.1 & \\
\hline No & 42 & 100.0 & 26 & 96.3 & & 34 & 33.7 & 32 & 22.9 & \\
\hline Unknown & & & & & & 2 & & 2 & & \\
\hline Treatments & & & & & 0.77 & & & & & 0.14 \\
\hline Surgery alone & 11 & 26.2 & 6 & 23.1 & & 31 & 31.0 & 32 & 22.5 & \\
\hline $\begin{array}{l}\text { Surgery } \pm \text { radiother- } \\
\text { apy } \pm \text { chemotherapy }\end{array}$ & 31 & 73.8 & 20 & 76.9 & & 69 & 69.0 & 110 & 77.5 & \\
\hline Unknown & 0 & & 1 & & & 3 & & 0 & & \\
\hline
\end{tabular}

SD standard deviation, CCI Charlson Comorbidity Index

[23]. Radiotherapy lead to vaginal dryness conducting to sexual alteration. Vaginal suture conduct to anatomical modification and impact sexual activities. Moreover, compare to younger ones, outcome of older survivors of EC treated by radiotherapy is worse [14].
Concerning older OC survivors in this study, physical impairment was the only problem reported by the older ones compared to younger ones. This result corroborate that of Van Walree et al. [7]. In their study, they had found that physical functioning subscale score of older 


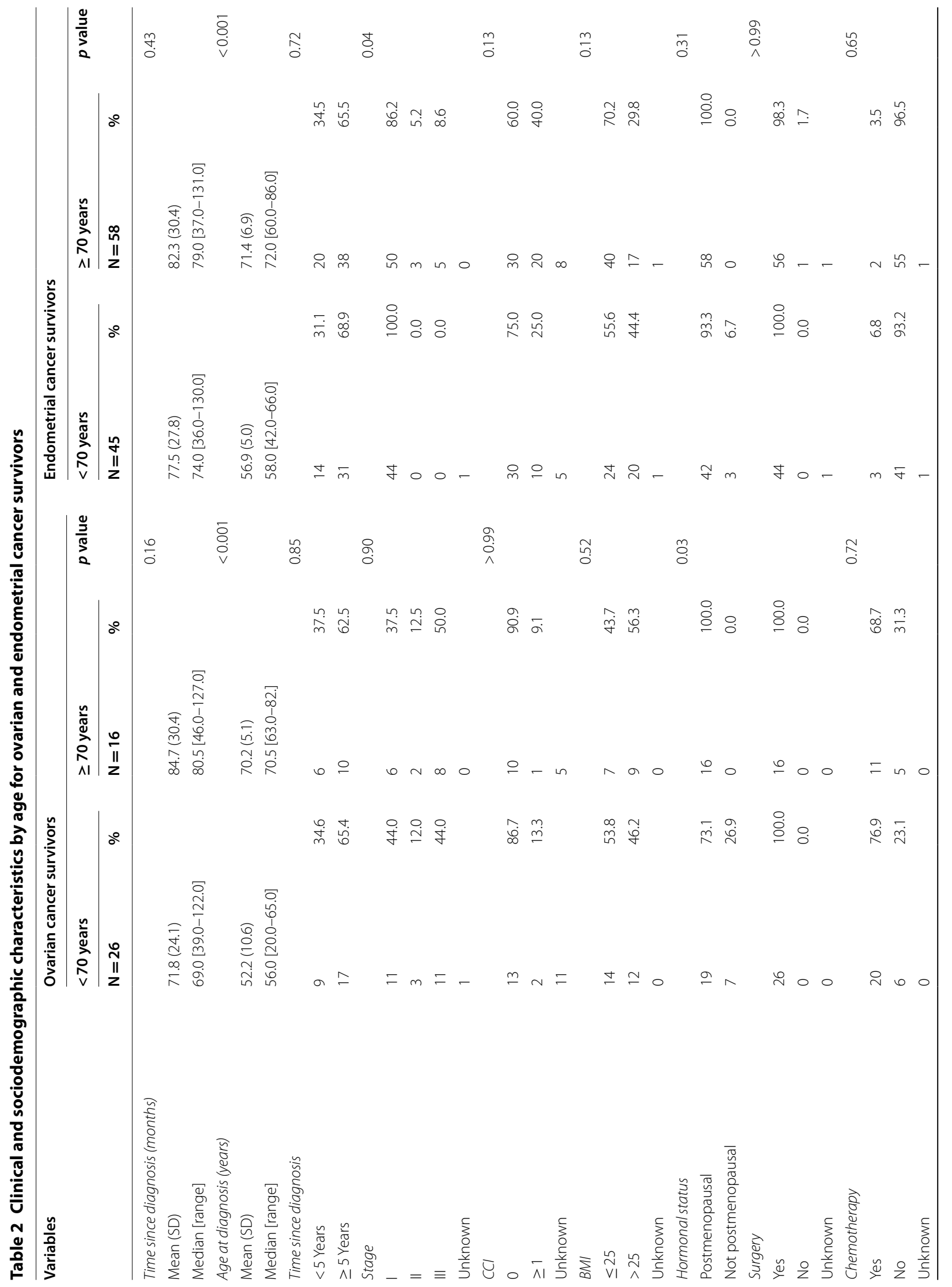




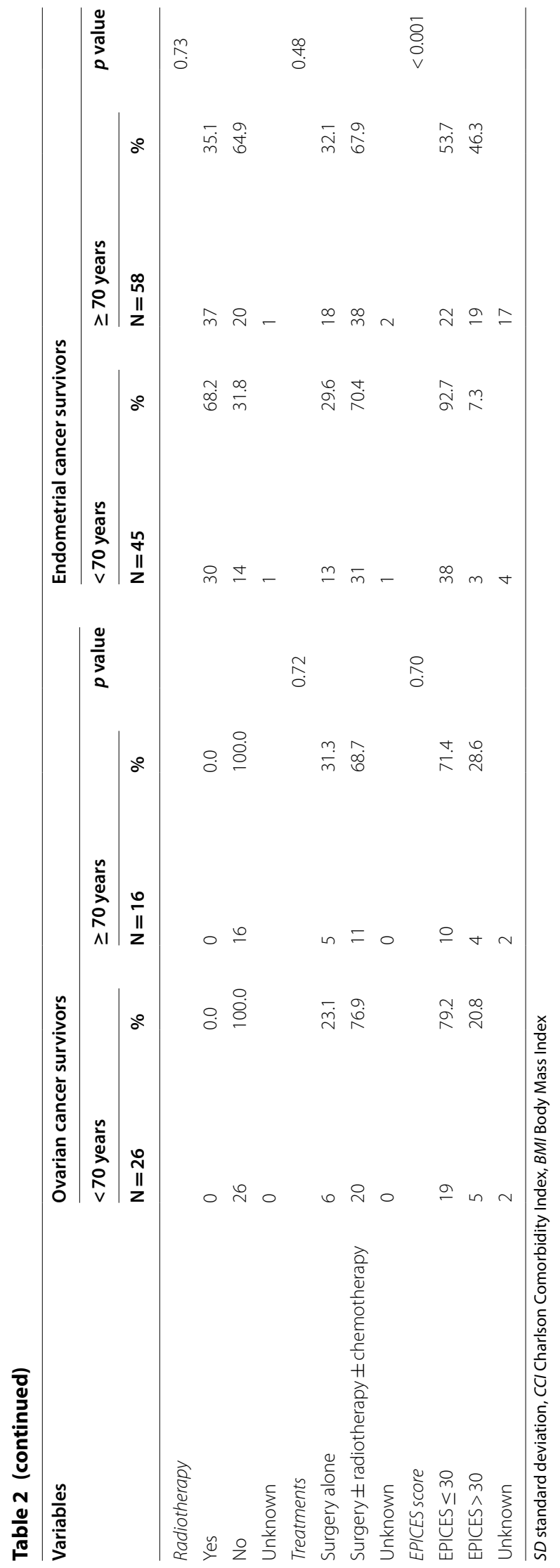


Table 3 HRQoL and sexual function scores by age among ovarian cancer survivors

\begin{tabular}{|c|c|c|c|c|c|c|c|}
\hline \multirow[t]{2}{*}{ Variables } & \multicolumn{3}{|c|}{$<70$ years } & \multicolumn{3}{|c|}{$\geq 70$ years } & \multirow[t]{2}{*}{$p$ value } \\
\hline & $N=26$ & Mean (SD) & Median (range) & $\mathrm{N}=16$ & Mean (SD) & Median (range) & \\
\hline \multicolumn{8}{|l|}{ HRQOL } \\
\hline General health & 26 & $57.3(21.2)$ & $60.0(25.0-100.0)$ & 16 & $50.6(18.9)$ & $60.0(25.0-85.0)$ & 0.30 \\
\hline Physical functioning & 25 & $84.0(26.9)$ & $100.0(0.0-100.0)$ & 16 & $59.4(36.4)$ & $75.0(0.0-100.0)$ & 0.01 \\
\hline Role physical & 26 & $67.8(21.3)$ & $62.5(37.5-100.0)$ & 16 & $52.3(28.9)$ & $50.0(0.0-100.0)$ & 0.08 \\
\hline Role emotional & 26 & $61.1(25.1)$ & $50.0(0.0-100.0)$ & 16 & $56.2(27.4)$ & $50.0(0.0-100.0)$ & 0.49 \\
\hline Bodily pain & 26 & $70.2(27.4)$ & $75.0(0.0-100.0)$ & 16 & $56.2(26.6)$ & $50.0(0.0-100.0)$ & 0.10 \\
\hline Mental health & 26 & $59.6(24.3)$ & $62.5(0.0-100.0)$ & 16 & $63.3(19.6)$ & $62.5(37.5-100.0)$ & 0.79 \\
\hline Vitality & 25 & $52(21.5)$ & $50.0(0.0-100.0)$ & 16 & $45.3(30.6)$ & $50.0(0.0-100.0)$ & 0.32 \\
\hline Social functioning & 26 & $64.4(26.6)$ & $75.0(0.0-100.0)$ & 16 & $64.1(27.3)$ & $62.5(25.0-100.0)$ & 0.89 \\
\hline PCS & 24 & $49(7.5)$ & $48.2(36.9-66.2)$ & 16 & $40.8(10.5)$ & $42.9(17.5-55.2)$ & 0.02 \\
\hline MCS & 24 & $41.6(10.5)$ & $40.4(17.5-60.3)$ & 16 & $43.6(10.0)$ & $43.3(30.1-66.0)$ & 0.69 \\
\hline \multicolumn{8}{|l|}{ Sexual function } \\
\hline Desire & 23 & $2.2(1.2)$ & $1.8(1.2-5.4)$ & 13 & $2(1.3)$ & $1.2(1.2-4.8)$ & 0.41 \\
\hline Arousal & 24 & $1.8(2.2)$ & $0.6(0.0-6.0)$ & 14 & $1.4(1.7)$ & $0.6(0.0-4.8)$ & 0.67 \\
\hline Pain & 21 & $1.9(2.5)$ & $0.0(0.0-6.0)$ & 11 & $0.7(1.6)$ & $0.0(0.0-4.8)$ & 0.15 \\
\hline Satisfaction & 15 & $3.3(2.0)$ & $3.2(0.8-6.0)$ & 5 & $3.8(2.0)$ & $4.4(0.8-6.0)$ & 0.63 \\
\hline Lubrication & 23 & $1.5(2.2)$ & $0.0(0.0-6.0)$ & 13 & $0.8(1.8)$ & $0.0(0.0-6.0)$ & 0.68 \\
\hline Orgasm & 24 & $1.7(2.3)$ & $0.0(0.0-6.0)$ & 13 & $0.8(1.6)$ & $0.0(0.0-4.4)$ & 0.23 \\
\hline Global Score & 15 & $15.4(12.3)$ & $22.1(2.0-35.4)$ & 4 & 16.3 (9.6) & $18.7(3.5-24.2)$ & 0.88 \\
\hline
\end{tabular}

HRQoL Health-Related Quality of Life, PCS Physical Component Score, MCS Mental Component Score, SD standard deviation

Table 4 HRQoL and sexual function scores by age among endometrial cancer survivors

\begin{tabular}{|c|c|c|c|c|c|c|c|}
\hline \multirow[t]{2}{*}{ Variables } & \multicolumn{3}{|c|}{$<70$ years } & \multicolumn{3}{|c|}{$\geq 70$ years } & \multirow[t]{2}{*}{$p$ value } \\
\hline & $N=45$ & Mean (SD) & Median (range) & $N=58$ & Mean (SD) & Median (range) & \\
\hline \multicolumn{8}{|l|}{ HRQoL } \\
\hline General health & 44 & $64.4(22.8)$ & $60.0(25.0-100.0)$ & 57 & $52.7(21.7)$ & $60.0(0.0-100.0)$ & 0.01 \\
\hline Physical functioning & 44 & $73.9(32.3)$ & $87.5(0.0-100.0)$ & 55 & $43.2(37.4)$ & $50.0(0.0-100.0)$ & $<0.001$ \\
\hline Role physical & 44 & $67.6(30.5)$ & $75.0(0.0-100.0)$ & 56 & $45.5(27.8)$ & $50.0(0.0-100.0)$ & 0.001 \\
\hline Role emotional & 45 & $65.3(27.3)$ & $62.5(0.0-100.0)$ & 53 & $52.4(26.4)$ & $50.0(0.0-100.0)$ & 0.02 \\
\hline Bodily pain & 43 & $75.0(27.8)$ & $75.0(0.0-100.0)$ & 55 & $54.1(26.7)$ & $50.0(0.0-100.0)$ & 0.001 \\
\hline Mental health & 44 & $60.5(20.2)$ & $62.5(12.5-100.0)$ & 56 & $56.2(20.8)$ & $50.0(0.0-100.0)$ & 0.28 \\
\hline Vitality & 43 & $47.1(27.4)$ & $50.0(0.0-100.0)$ & 54 & $43.0(25.0)$ & $50.0(0.0-100.0)$ & 0.35 \\
\hline Social functioning & 44 & $72.2(26.0)$ & $75.0(0.0-100.0)$ & 56 & $63.4(24.7)$ & $75.0(25.0-100.0)$ & 0.07 \\
\hline PCS & 41 & $48.2(10.6)$ & $50.3(20.4-61.5)$ & 51 & $37.8(9.9)$ & $38.3(16.7-60.8)$ & $<0.001$ \\
\hline MCS & 41 & $43.4(10.9)$ & $44.8(16.9-61.1)$ & 51 & $42.2(9.1)$ & $41.9(25.6-62.4)$ & 0.38 \\
\hline \multicolumn{8}{|l|}{ Sexual function } \\
\hline Desire & 43 & $2.4(1.2)$ & $2.4(1.2-6.0)$ & 46 & $1.7(0.9)$ & $1.2(1.2-3.6)$ & 0.01 \\
\hline Arousal & 43 & $2.1(2.0)$ & $1.8(0.0-6.0)$ & 42 & $1.0(1.3)$ & $0.3(0.0-4.5)$ & 0.01 \\
\hline Pain & 40 & $1.7(2.2)$ & $0.0(0.0-6.0)$ & 42 & $0.9(1.8)$ & $0.0(0.0-6.0)$ & 0.07 \\
\hline Satisfaction & 27 & $3.6(1.8)$ & $4.0(0.8-6.0)$ & 18 & $2.9(1.5)$ & $3(0.8-5.2)$ & 0.14 \\
\hline Lubrication & 42 & $1.7(2.1)$ & $0.6(0.0-6.0)$ & 42 & $1.1(1.8)$ & $0.0(0.0-6.0)$ & 0.07 \\
\hline Orgasm & 43 & $2.0(2.3)$ & $1.2(0.0-6.0)$ & 44 & $0.8(1.4)$ & $0.0(0.0-4.8)$ & 0.01 \\
\hline Global score & 26 & $17.4(10.5)$ & $19.1(2.0-36.0)$ & 18 & $13.5(8.7)$ & $14.8(2.0-26.8)$ & 0.20 \\
\hline
\end{tabular}


Table 5 Social support, anxiety and depression by age among ovarian endometrial cancer survivors

\begin{tabular}{|c|c|c|c|c|c|c|c|}
\hline \multirow[t]{2}{*}{ Variables } & \multicolumn{3}{|c|}{$<70$ years } & \multicolumn{3}{|c|}{$\geq 70$ years } & \multirow[t]{2}{*}{$p$ value } \\
\hline & $\mathbf{N}$ & Mean (SD) & Median (range) & $\mathbf{N}$ & Mean (SD) & Median (range) & \\
\hline Ovarian cancer & $N=26$ & & & $N=16$ & & & \\
\hline \multicolumn{8}{|l|}{ Social support } \\
\hline Social support availability & 22 & $15.4(9.1)$ & $15.0(0.0-36.0)$ & 11 & $11.9(4.6)$ & $11.0(6.0-22.0)$ & 0.32 \\
\hline Social support satisfaction & 18 & $29.0(7.1)$ & $30.0(6.0-36.0)$ & 10 & $29.2(4.5)$ & $29.0(22.0-36.0)$ & 0.56 \\
\hline \multicolumn{8}{|l|}{ HADS scores } \\
\hline Anxiety & 25 & $8.8(4.9)$ & $9.0(0.0-19.0)$ & 16 & $8.2(3.7)$ & $7.5(3.0-15.0)$ & 0.71 \\
\hline Depression & 24 & $5.0(2.8)$ & $5.0(1.0-10.0)$ & 15 & $6.1(3.6)$ & $7.0(0.0-11.0)$ & 0.35 \\
\hline \multicolumn{8}{|l|}{ Anxiety (\%) } \\
\hline$<11$ & 15 & 60.0 & & 10 & 62.5 & & \\
\hline$\geq 11$ & 10 & 40.0 & & 6 & 37.5 & & \\
\hline Missing & 1 & & & 0 & & & \\
\hline Depression (\%) & & & & & & & 0.14 \\
\hline$<11$ & 24 & 100.0 & & 13 & 86.7 & & \\
\hline$\geq 11$ & 0 & 0.0 & & 2 & 13.3 & & \\
\hline Missing & 2 & & & 1 & & & \\
\hline Endometrial cancer & $N=45$ & & & $N=58$ & & & \\
\hline \multicolumn{8}{|l|}{ Social support } \\
\hline Social support availability & 39 & $14.2(7.5)$ & $12.0(4.0-31.0)$ & 43 & $15.6(10.5)$ & $14.0(0.0-42.0)$ & 0.86 \\
\hline Social support satisfaction & 35 & $28.7(5.7)$ & $29.0(16.0-36.0)$ & 34 & $29.3(6.1)$ & $30.0(6.0-36.0)$ & 0.54 \\
\hline \multicolumn{8}{|l|}{ HADS scores } \\
\hline Anxiety & 44 & $9.0(4.1)$ & $9(2.0-20.0)$ & 48 & $8.7(4.3)$ & $7.0(0.0-18.0)$ & 0.64 \\
\hline Depression & 43 & $5.8(4.8)$ & $6(0.0-20.0)$ & 49 & $6.6(3.4)$ & $6.0(1.0-15.0)$ & 0.11 \\
\hline Anxiety (\%) & & & & & & & 0.46 \\
\hline$<11$ & 28 & 63.6 & & 34 & 70.8 & & \\
\hline$\geq 11$ & 16 & 36.4 & & 14 & 29.2 & & \\
\hline Missing & 1 & & & 10 & & & \\
\hline Depression (\%) & & & & & & & 0.65 \\
\hline$<11$ & 39 & 90.7 & & 43 & 87.8 & & \\
\hline$\geq 11$ & 4 & 9.3 & & 6 & 12.2 & & \\
\hline Missing & 2 & & & 9 & & & \\
\hline
\end{tabular}

SD standard deviation, HADS Hospital Anxiety and Depression Scale

women with $\mathrm{OC}$ is worse than those of younger ones. Comorbidities are less present among those women and cannot explain the difference. This physical impairment may be chemotherapies-related particularly with platin and taxan. Fatigue and neuropathy are the most common side effects of these treatments. Recovery could be slower in older people and conduct in more physical impairment. Nevertheless, we can excluded the possibility of lack of power due the low number of OC survivors.

Sexual function scores were low regardless of age and cancer location with lower scores in EC survivors aged 70 and more. Endometrial and ovarian cancers being part of gynecological cancers are known to be associated with a greater risk of sexual impairment particularly due to their location (genital tract) and treatment which is localized (as surgery and other) [24]. Sexual issues go unaddressed for many cancer survivors, particularly women [25]. There is a great lack of assessment of sexual function during medical monitoring after treatment. Few providers often ask patients about sexual concerns and patients don't really raised the topic [26]. Women with gynecologic cancers also pointed worries and lack of information to worsen sexual impairment [27]. So, a sexual consultation could be a way to fought sexual dysfunction despite treatment sequelae. Nevertheless, we must be cautious in interpreting these results because of the high level of missing data in sexual dysfunction, particularly for satisfaction items.

Depression is considered as a poor prognostic marker of physical disability in elderly patients with 
Table 6 Significant determinants of health-related quality of life

\begin{tabular}{|c|c|c|c|c|}
\hline SF-12 significant dimensions & Variables & Estimate & Standard error & $p$ value \\
\hline \multicolumn{5}{|l|}{ Endometrial cancer } \\
\hline \multirow[t]{6}{*}{ Physical functioning ${ }^{a}$} & Charlson score at diagnosis & & & 0.0027 \\
\hline & 0 & 0 & & \\
\hline & $\geq 1$ & -18.6824 & 6.0810 & \\
\hline & Age by the time of survey & & & $<0.0001$ \\
\hline & $<70$ & 25.9086 & 5.6407 & \\
\hline & $\geq 70$ & 0 & & \\
\hline \multirow[t]{12}{*}{ Bodily pain ${ }^{b}$} & BMI & & & 0.0028 \\
\hline & $\leq 25$ & 0 & & \\
\hline & $>25$ & -14.2069 & 4.6464 & \\
\hline & Depression & & & 0.0037 \\
\hline & $<11$ & 0 & & \\
\hline & $\geq 11$ & -21.1004 & 7.1137 & \\
\hline & EPICES deprivation score & & & 0.0049 \\
\hline & $\leq 30$ & 0 & & \\
\hline & $>30$ & -14.8791 & 5.1845 & \\
\hline & Age by the time of survey & & & 0.0054 \\
\hline & $<70$ & 13.3102 & 4.6935 & \\
\hline & $\geq 70$ & 0 & & \\
\hline \multicolumn{5}{|l|}{ Ovarian cancer } \\
\hline \multirow[t]{3}{*}{ Physical functioning ${ }^{c}$} & Age by the time of survey & & & 0.0035 \\
\hline & $<70$ & 28.8333 & 9.1607 & \\
\hline & $\geq 70$ & 0 & & \\
\hline
\end{tabular}

a Adjusted on BMI, stage, comorbidity, time since diagnosis, depression, EPICES deprivation score, radiotherapy

b Stage, time since diagnosis, comorbidity, chemotherapy, radiotherapy

c BMI, anxiety, depression

cancer [28] during treatment. In this long term study, depression level is not different between older and younger survivors regardless of location.

Although a low rate response and a low number of patients, this study shows us long-term results. Moreover, the results of the study show that old patients respond to the solicitation. This result is along of that of Prieske et al. [29]. In their study assessing the disposition and apprehension of elderly patients (aged $\geq 65$ years old) with gynecological cancers toward study participation had found that old patients are generally willing to participate in clinical studies. Although recommendations have been made concerning the need for older patients to take part in research studies and randomized clinical trials devoted to HRQoL, much remains to be done to ensure that these measures are effective. Nevertheless, efforts have made recently to ensure that this is the case with some studies focusing on older patients being conducted [6, $7,23]$

\section{Conclusion}

In conclusion, this study shows us long-term results of HRQoL and sexual function of old patients with either endometrial or ovarian cancers. Older patients may have aging-associated frailties associated with comorbidities and geriatric syndromes. The more marked physical deterioration in EC survivors could be explained by the impact of treatments (radiotherapy versus chemotherapy) but also comorbidities, not to mention the intrinsic prognosis of cancers.

\section{Abbreviations}

HRQoL: Health-Related Quality Of Life; EC: Endometrial cancer; OC: Ovarian cancer; MD: Mean difference; SF-12: Medical Short Form 12; FSFI: Female Sexual Function Index; HADS: Hospital Anxiety and Depression Scale; SSQ6: Sarason Social Support Questionnaire; EPICES: Évaluation de la précarité et des inégalités de santé pour les centres d'examen de santé.

Acknowledgements

We thank Fiona Caulfield for English language editing. 


\section{Authors' contributions}

Study Concept and Design: AMK, LBL and TSDY. Acquisition of subjects and/ or data: ADJ, PA. Data analysis: AMK and TSDY. Interpretation of data: AMK, LBL, TSDY, VQ, SM, LF, ID. Preparation of manuscript: AMK, LBL, TSDY, VQ. All authors read and approved the final manuscript.

\section{Funding}

This study is not funded.

\section{Availability of data and materials}

Data are available on request from the authors.

\section{Ethical approval and consent to participate}

This study is an ancillary study. The primary study was performed in accordance with the Declaration of Helsinki and have received ethics approval. Indeed, the study was approved by the french national data protection authority (Commission nationale de l'informatique et des libertés MR003 Nº 1989764 V.0). Also, women have received legal information about the study. The response to the questionnaires constituted the women's consent to participate.

\section{Consent for publication}

Not applicable.

\section{Competing interests}

The authors declare that they have no competing interests.

\section{Author details}

${ }^{1}$ Epidemiology and Quality of Life Research Unit, Lipids, Nutrition, Cancer Research Center, INSERM U1231, Georges Francois Leclerc Centre - UNICANCER, 1 rue Professeur Marion, BP 77980, 21079 Dijon Cedex, France. ${ }^{2}$ Medical Oncology Department, Centre Georges-François Leclerc, 1 rue Pr. Marion, 21000 Dijon, France. ${ }^{3}$ Geriatric Oncology Coordination Unit in Burgundy, University Hospital, 21079 Dijon, France. ${ }^{4}$ Department of Geriatrics and Internal Medicine, Hospital of Champmaillot, University Hospital, 21079 Dijon, France. ${ }^{5}$ Oncology Centre of Park, 18 Cours du General De Gaulle, Dijon, France.

${ }^{6}$ Centre for Research in Epidemiology and Population Health (CESP), INSERM U1018, University Paris-Sud, UVSQ Gustave Roussy, Villejuif, France. ${ }^{7}$ National Quality of Life and Cancer Platform, Dijon, France.

Received: 6 July 2020 Accepted: 12 January 2021

Published online: 12 February 2021

\section{References}

1. Defossez G, Le Guyader-Peyrou S, Uhry Z, Grosclaude P, Colonna M, Dantony $\mathrm{E}$, et al. Estimations nationales de l'incidence et de la mortalité par cancer en France métropolitaine entre 1990 et 2018. Synthèse. Saint-Maurice : Santé publique France, 2019.

2. Heilmann T, Pfisterer J, Hempel AM, Saß S, Hedderich J, Pujade-Lauraine E, et al. Early treatment modifications improve chemotherapy adherence in ovarian cancer patients $\geq 70$ years. Gynecol Oncol. 2019;153(3):616-24.

3. Bourgin C, Saidani M, Poupon C, Cauchois A, Foucher F, Leveque J, et al. Endometrial cancer in elderly women: which disease, which surgical management? A systematic review of the literature. Eur J Surg Oncol. 2016;42(2):166-75.

4. Eggemann $\mathrm{H}$, Ignatov $\mathrm{T}$, Burger $\mathrm{E}$, Costa SD, Ignatov A. Management of elderly women with endometrial cancer. Gynecol Oncol. 2017;146(3):519-24

5. Poupon C, Bendifallah S, Ouldamer L, Canlorbe G, Raimond E, Hudry N, et al. Management and survival of elderly and very elderly patients with endometrial cancer: an age-stratified study of 1228 women from the FRANCOGYN group. Ann Surg Oncol. 2017;24(6):1667-76.

6. de Arruda FN, Oonk MHM, Mourits MJE, de Graeff P, Jalving M, de Bock $\mathrm{GH}$. Determinants of health-related quality of life in elderly ovarian cancer patients: the role of frailty and dependence. Gynecol Oncol. 2019;153(3):610-5.

7. van Walree IC, Hamaker ME, van de Poll-Franse LV, Vos MC, Boll D, van Huis-Tanja LH, et al. Older ovarian cancer survivors report lower long-term health-related quality of life than younger survivors: a study from the population-based profiles registry. Gynecol Oncol. 2019;153(2):391-8.

8. Pilleron S, Sarfati D, Janssen-Heijnen M, Vignat J, Ferlay J, Bray F, et al. Global cancer incidence in older adults, 2012 and 2035: a populationbased study. Int J Cancer. 2019;144(1):49-58.

9. Colombo N, Creutzberg C, Amant F, Bosse T, González-Martín A, Ledermann J, et al. ESMO-ESGO-ESTRO consensus conference on endometrial cancer. Int J Gynecol Cancer. 2016;26(1):2-30.

10. Ledermann JA, Raja FA, Fotopoulou C, Gonzalez-Martin A, Colombo N, Sessa C. Newly diagnosed and relapsed epithelial ovarian carcinoma: ESMO Clinical Practice Guidelines for diagnosis, treatment and follow-up. Ann Oncol. 2013;24(suppl_6):24-32. https://doi.org/10.1093/annonc/ mdt333.

11. Chéreau E, Ballester M, Selle F, Rouzier R, Daraï E. Ovarian cancer in the elderly: impact of surgery on morbidity and survival. Eur J Surg Oncol EJSO. 2011:37(6):537-42.

12. Greenwade MM, Moore KN, Gillen JM, Ding K, Rowland MR, Crim AK, et al. Factors influencing clinical trial enrollment among ovarian cancer patients. Gynecol Oncol. 2017;146(3):465-9.

13. Benito V, Lubrano A, Andújar M, Mori M, Federico M. Management of endometrial cancer in patients aged 80 years and older: identifying patients who may benefit from a curative treatment. Eur J Obstet Gynecol Reprod Biol. 2019;1(242):36-42.

14. Rovirosa Á, Cortés KS, Ascaso C, Glickman A, Valdés S, Herreros A, et al. Are endometrial cancer radiotherapy results age related? Clin Transl Oncol. 2018;20(11):1416-21.

15. Mamguem Kamga A, Dumas A, Joly F, Billa O, Simon J, Poillot M-L, et al. Long-term gynecological cancer survivors in Côte d'Or: health-related quality of life and living conditions. Oncologist. 2019;24(7):e490-500.

16. Gandek B, Ware JE, Aaronson NK, Apolone G, Bjorner JB, Brazier JE, et al. Cross-validation of item selection and scoring for the SF-12 Health Survey in nine countries: results from the IQOLA project. International quality of life assessment. J Clin Epidemiol. 1998;51(11):1171-8.

17. Rosen R, Brown C, Heiman J, Leiblum S, Meston C, Shabsigh R, et al. The Female Sexual Function Index (FSFI): a multidimensional self-report instrument for the assessment of female sexual function. J Sex Marital Ther. 2000;26(2):191-208.

18. Wylomanski S, Bouquin R, Philippe H-J, Poulin Y, Hanf M, Dréno B, et al. Psychometric properties of the French Female Sexual Function Index (FSFI). Qual Life Res Int J Qual Life Asp Treat Care Rehabil. 2014;23(7):2079-87.

19. Lepine JP, Godchau M, Brun P. Anxiety and depression in inpatients. Lancet Lond Engl. 1985;2(8469-70):1425-6. https://doi.org/10.1016/S0140 -6736(85)92589-9.

20. Rascle N, Bruchon-Schweitzer M, Sarason IG. Short form of Sarason's Social Support Questionnaire: French adaptation and validation. Psychol Rep. 2005;97(1):195-202.

21. Sass C, Moulin J-J, Guéguen R, Abric L, Dauphinot V, Dupré C, et al. Le score Epices: un score individuel de précarité. Construction du score et mesure des relations avec des données de santé, dans une population de 197389 personnes. Bull Épidémiologique Hebd. 2006; 14:93-6.

22. Marosi C, Köller M. Challenge of cancer in the elderly. ESMO Open. 2016;1(3):e000020.

23. Karabuga $H$, Gultekin M, Tulunay G, Yuce K, Ayhan A, Yuce D, et al. Assessing the quality of life in patients with endometrial cancer treated with adjuvant radiotherapy. Int J Gynecol Cancer. 2015;25(8):1526-33.

24. Levin AO, Carpenter KM, Fowler JM, Brothers BM, Andersen BL, Maxwell GL. Sexual morbidity associated with poorer psychological adjustment among gynecological cancer survivors. Int J Gynecol Cancer Off J Int Gynecol Cancer Soc. 2010;20(3):461-70.

25. Reese JB, Sorice K, Beach MC, Porter LS, Tulsky JA, Daly MB, et al. PatientProvider communication about sexual concerns in cancer: a systematic review. J Cancer Surviv Res Pract. 2017;11(2):175-88.

26. Valpey R, Kucherer S, Nguyen J. Sexual dysfunction in female cancer survivors: a narrative review. Gen Hosp Psychiatry. 2019;1(60):141-7.

27. Fischer OJ, Marguerie M, Brotto LA. Sexual function, quality of life, and experiences of women with ovarian cancer: a mixed-methods study. Sex Med. 2019;7(4):530-9.

28. Pamoukdjian F, Aparicio T, Zelek L, Boubaya M, Caillet P, François V, et al. Impaired mobility, depressed mood, cognitive impairment and polypharmacy are independently associated with disability in older cancer 
outpatients: the prospective Physical Frailty in Elderly Cancer patients (PF-EC) cohort study. J Geriatr Oncol. 2017:8(3):190-5

29. Prieske K, Trillsch F, Oskay-Özcelik G, Chekerov R, Bleich C, Oliveira-Ferrer $L$, et al. Participation of elderly gynecological cancer patients in clinical trials. Arch Gynecol Obstet. 2018;298(4):797-804.

30. Doran P, Burden S, Shryane N. Older people living well beyond cancer: the relationship between emotional support and quality of life. J Aging Health. 2018. https://doi.org/10.1177/0898264318799252.

\section{Publisher's Note}

Springer Nature remains neutral with regard to jurisdictional claims in published maps and institutional affiliations.
Ready to submit your research? Choose BMC and benefit from:

- fast, convenient online submission

- thorough peer review by experienced researchers in your field

- rapid publication on acceptance

- support for research data, including large and complex data types

- gold Open Access which fosters wider collaboration and increased citations

- maximum visibility for your research: over $100 \mathrm{M}$ website views per year

At BMC, research is always in progress.

Learn more biomedcentral.com/submissions 